\title{
GAME METHODOLOGY FOR DESIGN METHODS AND TOOLS SELECTION
}

\author{
Dr. Rafiq Ahmad \\ Assistant Professor, CECOS University, Peshawar, Pakistan \\ engrrafiq@gmail.com \\ Dr. Nathalie Lahonde, Dr. Jean-françois Omhover \\ CPI, Arts et Métiers ParisTech Centre de Paris, 151, Boulevard de l'Hôpital - 75013 Paris-France \\ nathalie.lahonde@ensam.eu, jean-francois.omhover@ensam.eu
}

\begin{abstract}
Design process optimisation and intelligence are the key words of today's scientific community. A proliferation of methods has made design a convoluted area. Designers are usually afraid of selecting one method/tool over another and even expert designers may not necessarily know which method is the best to use in which circumstances. This detailed study aims to optimise and simplify the selection process of general design methods and tools. It has been carried out to support designers' selection of methods/tools for general design. The proposed original methodology, named Design Game Matrix of Tool Selection (DG-MOTS) and based on the analogy of the game of Snakes and Ladders, has been validated by designers.
\end{abstract}

\section{Keywords}

Design optimisation, Design tools and methods selection, Decision during design, Snakes and Ladders game

\section{Introduction}

Designers experience difficulty in selecting the best methods or tools for a design. Many researchers have provided guides and methodologies for the process of selecting appropriate methods and tools but designers still lack confidence (Jones, 1992). Design methods and tools have many applications and benefits such as minimising costs, resources, errors, and time to market, providing innovative solutions, shortening the product development life cycle, providing new ideas and concepts, supporting design activities, increasing creativity, needs analysis, and improving the overall quality of the product or process. Every method and tool has its importance at its appropriate stage or process. The designer should know and use proven selection criteria for decision-making in order to provide a quality product to the market, while staying within all the constraints of the project. The design process relies on good decision making because a huge amount of production cost can be reduced if good decisions are applied during this phase. Methods and tools selection is a major part of this decision process.

\section{Method and Tools selection}

The wrong selection of methods or tools may lead to the loss of time, quality, cost and satisfaction in the product and sometimes even to the blockage of the design process. The real problem is to optimise the design process, improve the decision-making process globally and to provide ease-ofuse to the designer for better and efficient methods/tools selection. 
These decisions are especially critical for an innovative product where the final product is uncertain. Every designer has a different way to approach a specific design and hence their selection criteria, methodology and perception about methods/tools are different. As everyone is not aware of all the methods/tools available, it increases the complexity. A specific method/tool for each design stage is very difficult to select, due to methods and tools giving different results in different scenarios. Guidance is therefore required to select the most appropriate method or tool at the right stage of the process.

It is not possible to provide all the methods/tools used in the design process, but a sincere effort has been made to provide a complete list (see Figure 1).

Scenarios [needs discovery], Focus group [Need elicitation], Brainstorming (Need elicitation), Questionnaire, Delphi Method [Generation], Objective tree, Benchmarking, Interview Method,

Performance specification, Functional analysis, Quality function deployment, Scenarios [creativity], Morphological chart or matrix, Updating functional analysis, House of quality, Value analysis, Brainstorming [generation], Brainwriting method [6-3-5 method], Mind mapping, Sketching or model making, Database or knowledge-based searching, Reverse Brainstorming, Idea generation, Synectics (analogies), Ladder of abstraction, Design by drawing, Story board, Sketches, Mockups, Idea cards, Test scenarios, Pahl \& Beitz Utility theory, Marsh AHP method, Pugh's evaluation method, Thurston's Fuzzy Set method, Focus group [evaluation], Brainstorming [evaluation], Scenarios [evaluation], Itemised response method, Voting method, Expert analysis, PMI Method, Fish bone diagram, VMEA, Standard drawing conventions, Scale drawings, Prototypes [layouts], CSP Method, CAD, Risk analysis tool, FMEA, Check lists, Models, Prototypes, Design of experiment, Computer Simulations, Finite elements methods, Rapid prototyping, Weighted objectives.

Figure 1. List of methods/tools offered for use in the DG-MOTS methodology

The Design Game - Matrix of Tool Selection (DG-MOTS) methodology described in this paper is based on the analogy of Snakes and Ladders game. It aims to make the decision-making process simpler but more interesting. It highlights areas of difficulty in the design process such as where it is not possible to make a choice specifically for the embodiment and detailed design phase. The design process combines numerous methods/tools that can be classified into different categories. Some of these methods/tools are basic processing that progress the process, while others provide only support for different/specific activities. As no process is totally similar to the other, it is not necessarily so that results produced from using one method or tool would produce the same results in another type of design. Relying on past experience may therefore cause problems for the designers in their decision-making.

\section{Design Game Matrix of Tool Selection (DG-MOTS) Methodology}

The DG-MOTS methodology is explained in detail in this section. As noted, DG-MOTS uses the Snakes and Ladders game for providing assistance to the designer for quick design and risks avoidance by selecting better design methods and tools. These methods/tools should be compatible with each design stage and provide a simple sequential way of design to the designer. Methods and tools are placed according to their inputs and outputs from/to the design process. The main focus for the methodology is the methods/tools selection during design Task clarification and Conceptual phases. Users may not agree with the methods and tools included in the Embodiment design phase, because it is difficult to generalise methods/tools due to differences between processes. 
Snakes and Ladders is a classic board game (Althoen, 1993), played between two or more players on a board of usually 100 squares. The goal of the game is to reach the end of the board by rolling the dice and moving that many squares. If the player lands on a ladder, they take a shortcut up the board, while landing on a snake moves the player back to its tail point. DG-MOTS methodology utilises the same principle of this game. Selecting a good method/tool can allow the designer to skip some design steps and accelerate the design process, while a poor selection can require them to restart several steps. The definition of 'Snakes and Ladders' used in this methodology is given below:

Snakes: Punishment (after accumulating risk or after inspection), requiring restarting previous design steps because of the designer's incorrect method/tool selection.

Ladders: Designer's reward/bonus for correct method/tool selection, skipping some steps in the design process.

The DG-MOTS methodology is shown in Figure 2. It should be noted that snakes and ladders are not defined for each risk or reward/bonus but are provided in the diagram so that the user can understand the possibility of risk or bonus at those steps. If the designer sees a Snake at their stage, it means that the risk of restarting some steps if a wrong method or tool is used at that point is present. A designer will know if a wrong method is selected after answering a check question at the end of each design phase, for example not having a feasible concept by Checkpoint 3 (see Figure 3). This risk depends on each process and user interpretations or perception. Ladders show opportunities for advancement at that point and again it depends on the process and user interpretations/perception. The placement of the Snakes and Ladders could be different for different design processes, which is why no definitive rule is provided here.

Snakes (punishments) and Ladders (rewards) are present at each step of the design process, and can be used to enhance the quality of the product and minimise the total time for a design process. For example, if time management is an important issue then eliminating some design steps by using Ladders will reduce the final design output time. Similarly, if a high quality product is required then more weight can be given to Snakes, while Ladders must be avoided in order to use each and every step of the design process. Hence, a compromise on product quality can gain design time and vice versa.

This methodology covers all the four phases of design:

1. Preparatory phase (Star 1$)$

2. Task clarification phase (Stars 2-4)

3. Conceptual design phase (Stars 5-9)

4. Embodiment and detailed design phase (Stars 10-12).

Note: All movement is at star numbers provided from 1 to 12 in DG-MOTS diagram unless Ladder or Snake interrupt the forward design movement 


\begin{tabular}{|c|c|c|c|c|}
\hline \multicolumn{5}{|c|}{ Design Game Matrix Of Tools Selection (DG-MOTS) } \\
\hline $\begin{array}{c}\text { Step status at } \\
\text { the startiend of } \\
\text { each phases } \\
\end{array}$ & Preparation completed & Start Clarification of Task & Few generated concepts & $\begin{array}{c}\text { Starting Embodiment } \\
\text { design and Detailed design }\end{array}$ \\
\hline $\begin{array}{c}\begin{array}{c}\text { Design brief } \\
\text { IIssue }\end{array} \\
\text { START }\end{array}$ & $\begin{array}{l}\text { Scenarios } \\
\text { (Needs discovery), Focus } \\
\text { group (Needs elicitation), } \\
\text { Brainstorming (Needs } \\
\text { elicitation), Questionnaire. }\end{array}$ & $\begin{array}{l}\text { Objective tree, Benchmarking, Delphi } \\
\text { Method (Generation). }\end{array}$ & Fish bone diagram, VMEA. & Design by drawing, \\
\hline $\begin{array}{l}\text { Task } \\
\text { clarified }\end{array}$ & $\begin{array}{l}\text { Performance specification, } \\
\text { Functional analysis. }\end{array}$ & $\begin{array}{l}\text { Focus group (Needs elicitation), } \\
\text { Scenarios (Needs discovery), Interview } \\
\text { Method, Questionnaire. }\end{array}$ & $\begin{array}{l}\text { Pahl \& Beitz (1996), Marsh AHP method (1991), } \\
\text { Pugh's evaluation method (1994), QFD matrix } \\
\text { method, Thurston's fuzzy set method, Focus } \\
\text { group (Evaluation), Brainstorming (Evaluation), } \\
\text { Scenarios (Evaluation), Itemised response } \\
8 \text { method, Voting method, } \\
8 \text { Expert analysis, PMI Method. }\end{array}$ & $\begin{array}{l}\text { Standard drawing } \\
\text { conventions, Scale drawings, } \\
\text { Prototypes (Layouts), (CSP } \\
\text { Method), CAD, Risk analysis } \\
\text { tool, FMEA, Check lists. }\end{array}$ \\
\hline $\begin{array}{l}\text { Concepts } \\
\text { initiation }\end{array}$ & $\begin{array}{l}\text { Quality function deployment, } \\
\text { Scenarios (Creativity), } \\
\text { Morphological chart. }\end{array}$ & $\begin{array}{l}\text { Brainwriting method (6-3-5 method), } \\
\text { Mind mapping, Sketching or model } \\
\text { making, Database or knowledge- } \\
\text { based searching, Reverse } \\
\text { Brainstorming, Benchmarking, Idea } \\
\text { generation, Synectics, Ladder of } \\
\text { abstraction. }\end{array}$ & $\begin{array}{l}\text { Design by drawing, Story board, Sketches, } \\
\text { Mockups, Idea Cards. }\end{array}$ & $\begin{array}{l}\text { 11 } \\
\text { Models, Prototypes, Design of } \\
\text { experiment, Computer } \\
\text { Simulations, CSP Method, } \\
\text { Morphological Matrix, Finite } \\
\text { elements methods. }\end{array}$ \\
\hline \multicolumn{5}{|l|}{$\begin{array}{l}\text { Validated } \\
\text { design }\end{array}$} \\
\hline Step status & Preparatory phase & Task clarification phase & Conceptual design phase & $\begin{array}{l}\text { Embodiment and Detailed } \\
\text { design phase }\end{array}$ \\
\hline
\end{tabular}

Figure 1: DG-MOTS 
These phases are differentiated by their background colour and star numbers. The first column and the first row give the process status when user is moving through certain design states. Star numbers represent the sequential way of selecting tools and moving forward to design process. Three indicators (squares) on each transfer boundary between phases are used for testing (red rectangular check). Each test consists of a question written beneath the matrix.

A general flowchart for DG-MOTS is as shown in Figure 2 with numbers representing the procedural steps to be followed.

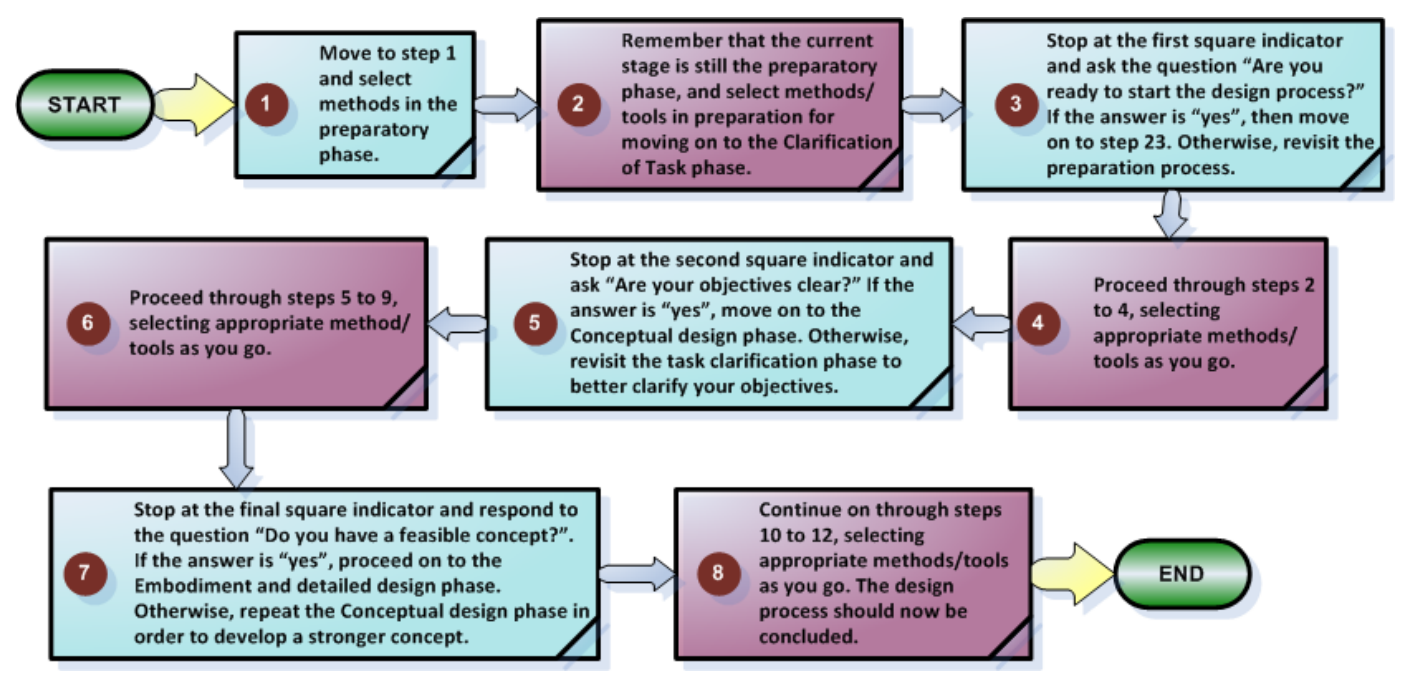

Figure 2: DG-MOTS flowchart

\section{The design decision process}

Many researchers have provided guides and methodologies for methods and tools selection process but still this decision process area lacks confidence on selected methods. The Input-Output chart (Jones, 1992) provides some states of the design process and includes some methods of design process but it is unsuitable for the whole design process. It also includes some backtracking methods which are not present in our case. This is because we believe that methods in design process should only be used for forward motion and not for backtracking. The Input-Output chart does not illustrate any phase of the design process, meaning that the designer cannot be sure about their exact position within the design process. The most important difference and advantage of the DG-MOTS methodologies presented in this paper is that they are more flexible for new methods. Since this methodology clearly gives the current and future status during the design process, it is much easier to add more design methods and tools into the methodology. The only requirement is to be clear about the inputs and outputs of the method/tool that derives its state during design process provided by the DG-MOTS methodology.

Another methods/tools selection methodology is Lopez-Mesa's (2002) I-A characteristic diagram which shows the difference between Innovative and Adaptive methods as well as Divergent and Convergent methods used in the design process. It also shows links between Innovative divergent, Innovative convergent, Adaptive divergent and Adaptive convergent methods. However, since the design process varies from product to product, uncertainty regarding this classification also increases. The I-A methodology mainly focuses on the four classifications of methods; divergent, convergent, innovative and adaptive. A designer must be knowledgeable enough to know the status of the specific design method in order to use this diagram. The I-A characteristic classification diagram is good for understanding the nature of design methods/tools but it does not provide a clear perspective and number of methods/tools selection at each step and phase. The 
boundary between innovative and adaptive methods is not clear, leading to further uncertainties.

The Pahl and Beitz (1996) model is integrated in the DG-MOTS methodology, helping to divide the matrix into four different design phases: Design Brief, Task Clarified, Concepts Initiation, and Validation. The Snakes and Ladders game analogy (Althoen, 1993) inspiration was the prime reason for the development of DG-MOTS methodology and has been used in many fields of research. For example, Witters, Kemp, and Means (2006) found that upstream protein kinases that act on the AMP-activated protein kinase is considered like a "Snakes and Ladders game," while Cave (2010) details the effect of ladder of investment by next generation access. DG-MOTS however represents the first time this game has been introduced in the design decision process. A comparison study of different designers' behaviour by Gunther and Ehrlenspiel (1999) that places more emphasis on current problematic of behaviors towards methods/tools selection. Some methods/tools definitions for better placement in the design process are taken from the work of Barone, Lombardo, and Tarantino (2009), Cross (2008) and King, and Sivaloganathan (1999).

\section{Results and discussions}

Validation of the DG-MOTS methodology was done through designer testing, which involved providing a sample of ten designers with a design brief to develop a strategy for a certain design process by using DG-MOTS to select tools and methods. At the conclusion of the exercise, the designers were interviewed to get qualitative results about their experience with DG-MOTS. Further feedback was received after their response to a questionnaire.

An evaluation criterion for Interview is to express whether the DG-MOTS was easy to use. The idea was to show areas for improvements and to express their view about its plus and minuses. Several questions asked of the designers are detailed below:

1. What do you think this methodology is lacking?

2. What particular aspect(s) of DG-MOTS did you like and for what reason?

3. What particular aspect(s) of DG-MOTS did you dislike and for what reason?

4. Do you think all the methods provided in this methodology are sufficient for the design brief provided?

5. After developing a design strategy through DG-MOTS, how interested would you be in future for using the proposed methodology?

- Not at all interested

- Not very interested

- Neither interested nor uninterested

\section{Qualitative results:}

The qualitative results given below are results from the designers' points of view about DG-MOTS methodology.

\section{Positive responses from the subjects include:}

- This methodology introduces new methods for learning.

- It was fun using this method for tools selection.

- It is an efficient method to solve a design problem.

- It helps in creativity for developing new tools.

- It is very much flexible for other methods. 
- It is a linear process, knowing where I am and where I am going.

- The Snakes and Ladders concept is awesome as it allows skipping the unnecessary steps and revising non-productive steps.

- Gives the feeling that you are not off track. Keep ones always on track.

- Can skip some steps easily to accelerate design process.

- Integration of phases that provide good indication of your current status in design process.

- Good applications will be in innovative design process because it is a creativity tool

\section{Negative responses from the subjects included:}

- No feedback system

- Needs more simplification

- Designer may not necessarily have access and knowledge of all tools present in the methodology.

- $\quad$ Limited in the current form.

- Feels [like] you [are] constrained to select among the methods provided because maybe the same process can be done with other tools.

\section{Perspective corrective actions:}

A feedback system is not included in this methodology but a few "red checks" for verifying methods selected at the end of each design phase will work for each phase transfer. Corrective work may be necessary if the checks give the designer the impression that they are not prepared. Snakes are also present to send you back when an incorrect method is selected, which also acts as a form of feedback. It is hoped to introduce more feedback systems in the future. Design validation methods and tools will also be added in the future. More design methods/tools can be introduced in the current form to make it more flexible and viable for more general application.

\section{Quantitative results:}

For quantitative evaluation, results of the questionnaire were analysed for the criteria presented in Table 01. Scores are assigned to each response to questions (see Annex 03) i.e. Strongly Agree =2, Agree $=1$, Neutral=0, Disagree $=-1$ and Strongly Disagree $=-2$.

The following questionnaire was formulated to show the basic criteria for qualitative evaluation, namely satisfaction, simplicity, suitability, organisation, time, flexibility, links, recommendations and interest.

1. Overall I am satisfied with DG-MOTS.

2. This is the simplest way ever used for methods/tools selection during a design process.

3. This methodology is suitable for any design process.

4. This methodology is properly organized i.e. explain each step sequentially.

5. This methodology is time consuming.

6. This DG-MOTS methodology is flexible for further methods/tools integration.

7. It provides a good link between different design phases.

8. It provides good (relevant) recommendations to the design seekers. 
The overall percentage of responses to each criterion is calculated as given in Table 01 . The quantitative result presented in Figure 3 shows positive values for most of the presented criterion and some neutral and negative values indicating room for improvements. The graph shows that the majority of responses and average values of the designers for the presented criteria are above the datum line " 0 ". It can therefore be surmised that this methodology is simple to use, flexible enough to provide room for the designer for further methods addition, properly organised, highly time saving, has a high satisfaction value and has generated interest for future use and applications.

Table 1: Criteria for DG-MOTS evaluation

\begin{tabular}{ccc}
\hline $\begin{array}{c}\text { Criterion } \\
\text { number }\end{array}$ & Different criteria & $\begin{array}{c}\text { Final result value } \\
(\% \text { age })\end{array}$ \\
\hline C1 & Overall satisfaction & 70 \\
C2 & Simplicity & 70 \\
C3 & Suitable for any design process & 55 \\
C4 & Properly organized & 67.5 \\
C5 & Time saving & 80 \\
C6 & Flexible & 72.5 \\
C7 & Provide links between design phases & 67.5 \\
C8 & Provide good recommendations & 67.5 \\
C9 & Interest in future use & 82.5 \\
\hline
\end{tabular}

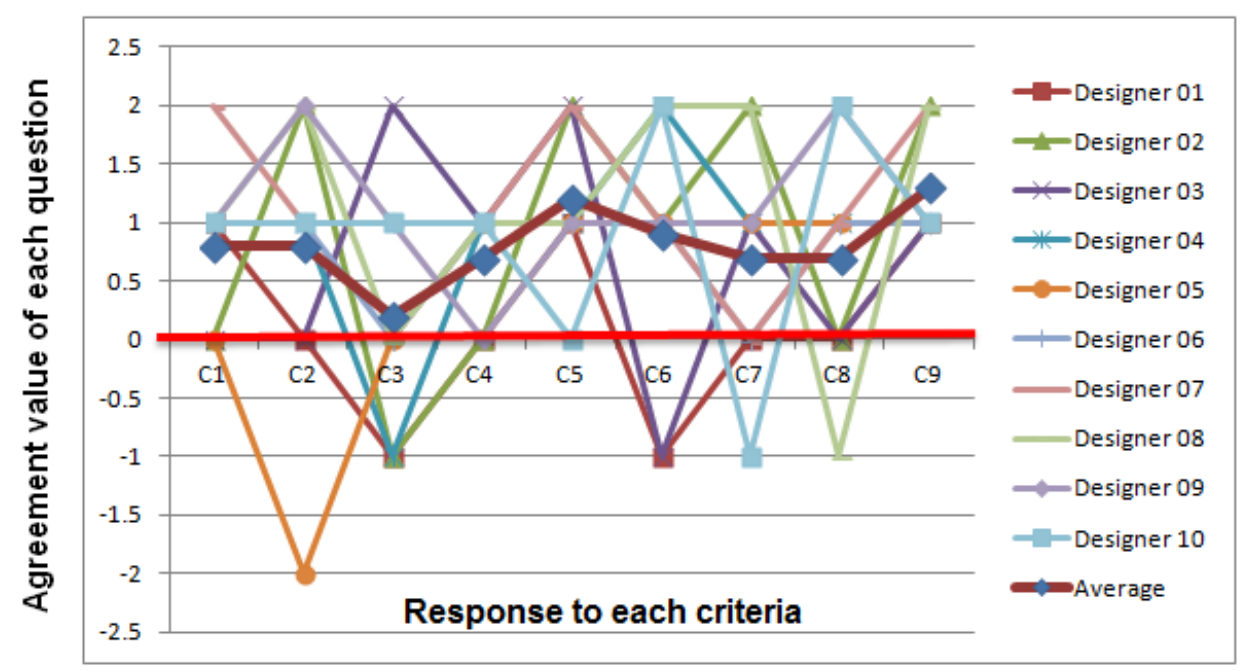

Figure 3: Graph of Quantitative results

\section{Conclusion}

Design process optimisation and intelligence is the prime motive of this research work. Methods and tools selection in a convoluted design process is very difficult especially for the new designers, and a notable need is addressed in this paper. DG-MOTS methodology is proposed to suggest right methods/tools selection during a design process. It is a creative tool that makes the design process more interesting and can be a better tool for naive designers' training because it engages the designer to the process in an interesting way. Results are validated by ten designers, responding positively to some evaluation criteria provided to them in the form of questionnaires and interview questions. In the future, more methods and tools will be added to the methodology, making it more comprehensive and applicable to any design process. 


\section{References}

Althoen, S. C., King, L., \& Schilling, K., (1993). How long is a game of snakes and ladders? The Mathematical Gazette, 77, 71 - 76.

Barone, S., Lombardo, A., \& Tarantino, P. (2009). Analysis of user needs for the redesign of a postural seat system. In P. Erto (Ed.), Statistics for innovation: Statistical design of “continuous" product (pp. 3-25). Milano, Italia: Springer.

Bouchard, C., Mantelet, F., Aoussat, A., Solves, C., Gonzalez, J. C., Pearce, K., van Lottum, C., \& Coleman, S. (2009). A European emotional investigation in the field of shoe design. International Journal of Product Development, 7(1/2), 3-27.

Cave, M., (2010), Snakes and ladders: Unbundling in a next generation world. Telecommunications Policy, 34(1-2), 80 - 85.

Cross, N., (2008). Engineering design methods: Strategies for product design $\left(4^{\text {th }}\right.$ ed.). Chichester, UK: John Wiley \& Sons.

Gunther, J., \& Ehrlenspiel, K. (1999). Comparing designers from practice and designers with systematic design education. Journal of Design Studies, 20(5), 439 - 451.

Jones, J. C. (1992). Design methods ( $2^{\text {nd }}$. ed.). New York: Wiley \& Sons.

King, A.M., \& Sivaloganathan, S. (1999). Development of a methodology for concept selection in flexible design strategies. Journal of Engineering Design, 10(4), 329-349.

Lopez-Mesa, B., Thompson, G., \& Williander, M., (2002), Managing uncertainty in the design and development process by appropriate methods selection. Paper presented at International Design Conference - Design 2002, Dubrovnik.

Pahl, G., \& Beitz, W.n(1996). Engineering design: A systematic approach. Springer-Verlag: London.

Witters, L. A., Kemp, B. E., \& Means, A. R., (2006). Chutes and ladders: The search for protein kinases that act on AMPK. Trends in Biochemical Sciences, 31(1), $13-16$.

Copyright @ 2014 Rafiq Ahmad, Nathalie Lahonde, Jean-françois Omhover 